\title{
CHANGE DETECTION AND GIS-BASED FUZZY AHP TO EVALUATE THE DEGRADATION AND RECLAMATION LAND OF TIKRIT CITY, IRAQ
}

\author{
Muntadher Aidi SHAREEF(1) ${ }^{*}$, Mohammed Hashim AMEEN $^{2}$, Qayssar Mahmood AJAJ ${ }^{1}$ \\ ${ }^{1}$ Department of Surveying Techniques Engineering, Technical College of Kirkuk, \\ Northern Technical University, Baghdad Road, 36001 Kirkuk, Iraq \\ ${ }^{2}$ Department of Environment Engineering, Engineering College, Tikrit University, Tikrit, Iraq
}

Received 23 November 2019; accepted 06 December 2020

\begin{abstract}
LULC factors in Tikrit city (Iraq) and the neighboring municipalities are studied among 1989, 2002 and 2015 using various techniques of remote sensing, geographical information system (GIS), and fuzzy analytical hierarchy process (FAHP). Satellite imagery with GIS helped to assess the standard LULC changes in the long term period. FAHP permitted estimating the importance of various LULC by determination of the suitable weight for used factors and then producing the evaluating models. Using different techniques, two models were created (1) to estimate the degradation of the land (2) is generated to determine the reclamation of the area. The finding reveals that the a overall accuracy of $97.0939 \%, 98.9199 \%$ and $99.5817 \%$ or 1989,2002 and 2015 respectively. The outcomes also revealed that urban, vegetation, and water features area are developed in the long term (1989-2015) about 4.35\%, $4.28 \%$, and $1.49 \%$, respectively, while barren area is reduced about $5.57 \%$.The degradation map index showed that the lands strongly debased are these converted from vegetation to barren, followed by moderate to high these changed from water areas to urban, while moderate degradation is noticed of urban transformed to barren soil. Contrary, the reclamation map index illustrated that the lands are powerfully transformed from barren to the vegetation and followed by those converted from barren to the water, while barren transformed to the urban is marked as moderate reclamation. The transformation from urban to vegetation or water was classified as the low and deficient class to evaluate the area. The study is also revealed that the integration of remote sensing and GIS produces a successful method for LULC monitoring and managing the environment.
\end{abstract}

Keywords: LULC, FAHP, GIS, degradation map index, reclamation map index.

\section{Introduction}

The land and the resulting resources are used to meet the spiritual, cultural and social needs of humans. In this procedure, the human uses the land for various uses and applications. Transfornation land into agricultural areas or fields is to meet the needs for food and others transformed to the cities with rasing of the growing population (Aburas et al., 2019). The LULC change requires frequent management and monitoring to determine areas that are degraded or reclaimed. Land degradation lead to reduce of productivity and environmental decline, economic possibility, and the deterioration of biodiversity and difficulty. This generates to the lessening or damage of the recuperation mission of ecological system (An et al., 2017). Land degradation also negatively influences the environment. Water and air have contaminated by sand, compost, and insecticide from field land. Consequently, it is essential to investigate land degradation and to discover its conditions (Gao \& Liu, 2010). Early detection of land degradation is a significant impediment to the use of old warning systems, especially in low-density areas. Besides, the land degradation monitoring community can benefit from the experiences of deforestation monitoring projects, which have recognized the importance of local stakeholders and end-users for active development (Rocchini et al., 2016). The early detection of soil degradation, especially at low intensities, is a significant limit on the usability of early warning and tracking systems for degradation. The most critical advancement in this problem is the implementation of structural and real-time changing recognition, but further research remains necessary. Bayesian statistics, according to which model assumptions based on previous understanding, also may help to identify the anticipated trajectories of deviation (Higginbottom \& Symeonakis, 2014). The community of land degradation surveillance can also profit from experiments of observer

*Corresponding author. E-mail: muntadher.a.shareef@ntu.edu.iq

Copyright @ 2020 The Author(s). Published by Vilnius Gediminas Technical University

This is an Open Access article distributed under the terms of the Creative Commons Attribution License (http://creativecommons.org/licenses/by/4.0/), which permits unrestricted use, distribution, and reproduction in any medium, provided the original author and source are credited. 
deforestation projects that have recognized the significance of the active growth of local parties and end-users (Rocchini et al., 2016). Land debasement can investigated via various means, including field measurements and remote sensing. In contrast with the field visit, remote sensing technique reduce cost, time, effort and cover large area in one image. for this reason, this techniques is used for reporting the land status that influenced by degradation to different levels (Gao \& Liu, 2008). Remote sensing imaging of a wide variety of space and airborne sensors offers enormous amounts of information on our earth's surface for global and detailed assessment, detection, and tracking of changes (Xiao et al., 2006). The fast changes in land use and coverage, especially in developing countries, are often defined by widespread urban expansion, land degradation, or the conversion of agricultural land into shrimp farming, resulting in enormous environmental costs (Rawat \& Kumar, 2015). Land use/land cover (LULC) changes in land result from a complex set of environmental and social factors that lead to a shift in services to humans, the animal economy and the environment. In addition to the rapid changes experienced by the world in changes in land use, especially the conversion of land from one category to another (Hailemariam et al., 2016). During this period numerous both supervised and unsupervised classification algorithms have been developed to derive standard land cover maps. Classification of image can be defined as grouping image pixels or objects into selected classes for producing a thematic map (Ajaj et al., 2017). Continuous supervision of retrieved locations offers valuable data on the change in vegetation cover (Shareef et al., 2018). GIS presents a regularly utilized means to examine knowledge obtained from the LULC through remote sensing data and to identify and map the LULC changes. The fuzzy idea describes in reference (Shareef et al., 2014). It is a "class" with a continuum of membership grades. The debate focuses on the implementation of a conventional method that utilizes the notion of fuzzy devices and fuzzy logic to identify the probability of modifications from remotely sensed information suitably (Metternicht, 1999). In this study, to evaluate the influence of land development, we used several classes as a criterion in multi-criteria models such as urban, vegetation, barren area and water, which are derived from the change detection method. fuzzy analytical hierarchy process (fuzzy-AHP) represents the additional process that considers commonly employed by numerous authors (Feizizadeh et al., 2014) for solving the various fuzzy query. due to the lack of information regarding the study region has motivated us to carry the an investigation to assess the LULC and to produce the degradation and reclamation maps based on the development of the LULC features amonge 1989, 2002 and 2015 using remote sensing, GIS, and FAHP techniques.

\section{Materials and methods}

\subsection{Study area and data used}

Tikrit is located on the right bank of the Tigris River, with a distance of $180 \mathrm{~km}$ north of Baghdad, and $330 \mathrm{~km}$ south of Mosul. The geographic location of Tikrit is at the intersection of latitude $34^{\circ} 34^{\prime} 54^{\prime \prime} \mathrm{N}$ and longitude $43^{\circ} 50^{\prime} 38^{\prime \prime} \mathrm{E}$, as shown in Figure 1. It is tilted with a steep edge on the Tigris River, approximately $45-50$ meters high, and a semiundulating area of Tikrit rising 110 meters above sea level. The city is penetrated by valleys and reefs with the natural slope of the land from west to east and extends inside the western plateau of varying distances (Hadi et al., 2014). It includes the valley of Shishin and Rumi in the south and the great Qaim and Zellah in the north. Also, it is one of the important cities due to its importance, as itis the official and efficient center of the Salahaldin region.

Three types of landsat data includes Landsat- 5 Thematic Mapper (TM), Landsat-7 Enhanced Thematic Mapper Plus (ETM+), and Landsat-8 Operational Land

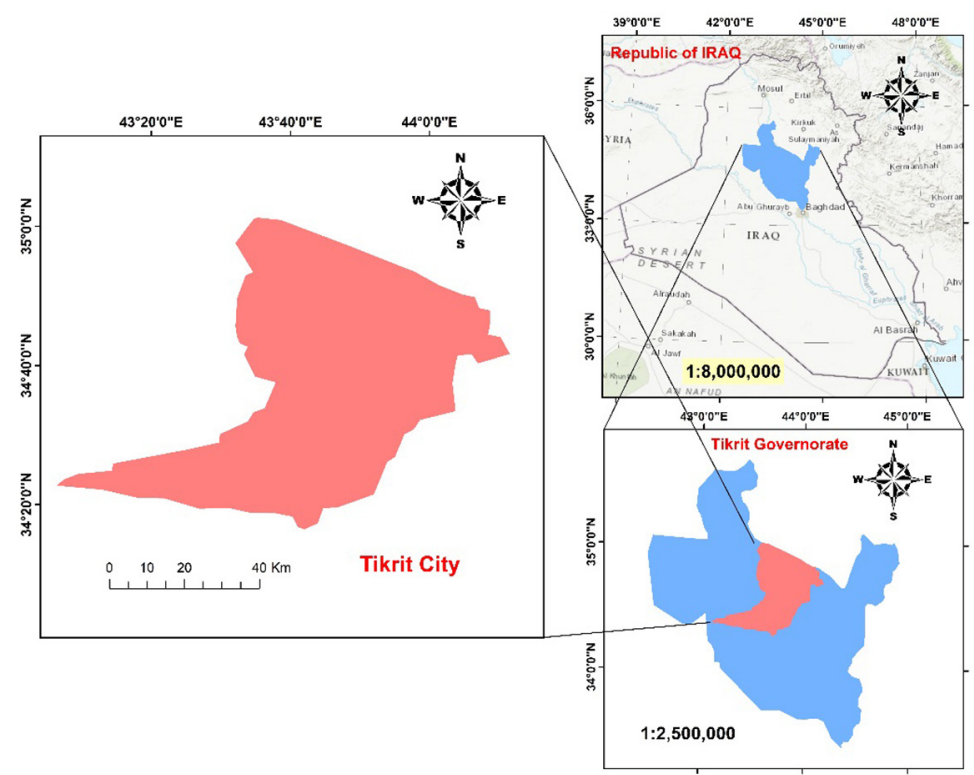

Figure 1. Study area 
Imager (OLI) were downloaded from U.S. Geological Survey Explore (USGS). The data images quired for 1989, 2002, and 2015 were chosen respectively at very near anniversary acquisition data (Table 1). Furthermore, a High-Resolution Ariel Photograph of Tikrit city was used as ancillary data for obtaining traing and testing data for classification process.

Table 1. Landsat image catogaries used in this study

\begin{tabular}{|l|c|c|c|c|}
\hline Satellite images & $\begin{array}{c}\text { Acquisition } \\
\text { date }\end{array}$ & $\begin{array}{c}\text { Band Reso- } \\
\text { lution (m) }\end{array}$ & $\begin{array}{c}\text { Path/ } \\
\text { Row }\end{array}$ & $\begin{array}{c}\text { Cloud } \\
\text { cover } \\
(\%)\end{array}$ \\
\hline Of Landsat-5 TM & $1989-07-07$ & $30 \mathrm{~m}$ & $169 / 036$ & 0 \\
\hline Landsat-7 ETM+ & $2002-07-27$ & $30 \mathrm{~m}$ & $169 / 036$ & 0 \\
\hline Landsat-8 & $2015-07-23$ & $30 \mathrm{~m}$ & $169 / 036$ & 0 \\
\hline
\end{tabular}

\subsection{Preprocessing and data preparation}

The flowchart of the overall methodologies in Figure 2 has two main parts, the first states the change detection

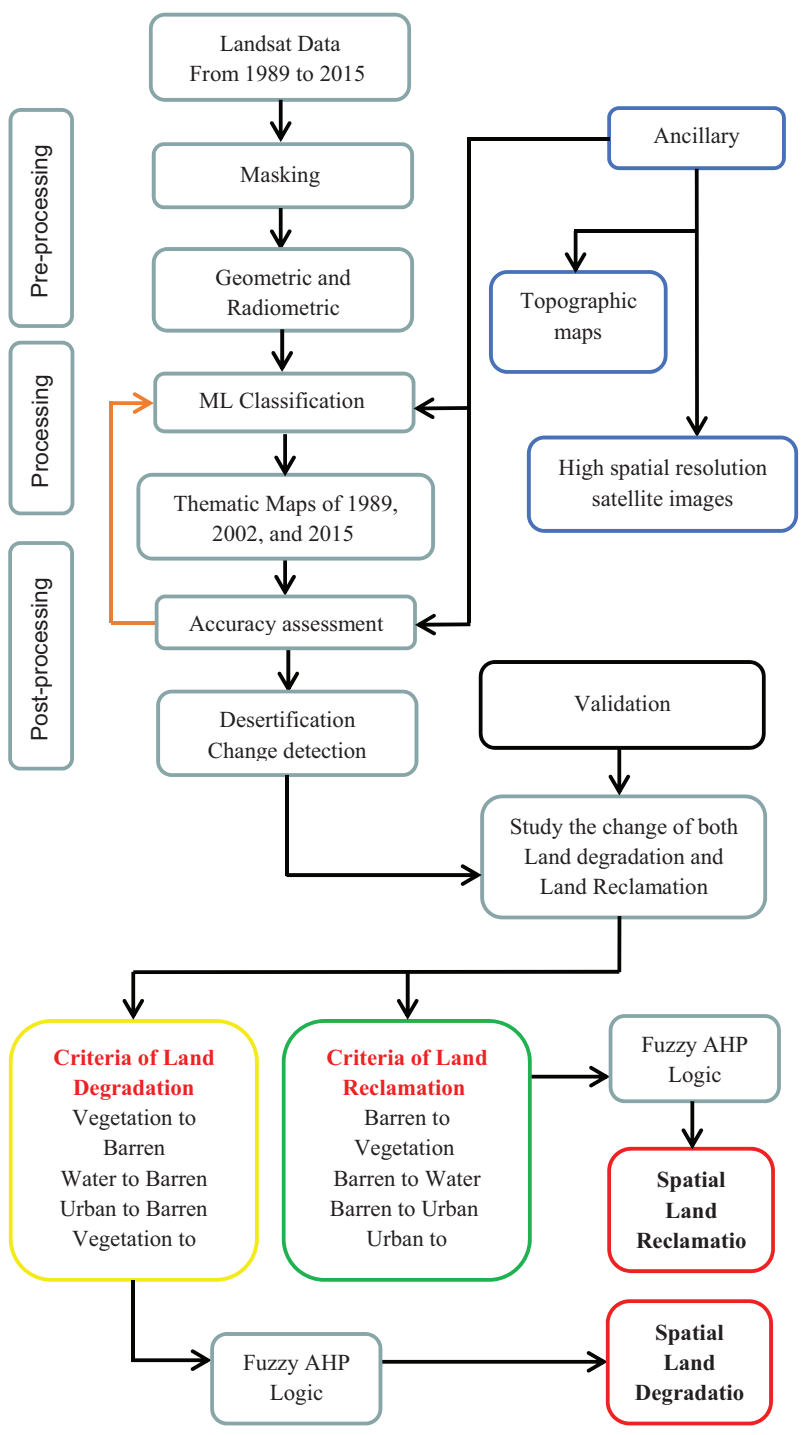

Figure 2. Shows the overall flowchart of methodology in this research analysis which consist of pre-processing the data, classification approach, and LULC change detection. The second includes Fuzzy AHP method passing through the fuzzification of the weights and creation the matrix (Figure 2)

\subsection{Classification and accuracy assessment}

The organization and categorizing of land cover/land use classes extracted from the image is a framework that can be defined as a classification scheme. A suitable classification scheme involves the classes which are essential for both studies as well as for discernible from the available data (Olofsson et al., 2013). Typically, each pixel is treated as an individual unit of values in several spectral bands. In this paper, we used a Maximum Likelihood algorithm (MLH) as supervised classification method, which is considered one of the most popular methods of supervised classification in various remote sensing application. In this study, four LULC classes were established, including Vegetation, urban, barren land, and water. The error matrix was performed to measure the accuracy of the classification which reports the degree of accuracy between the classified data and the training of the same data (Foody, 2002).

\subsection{Change detection analysis}

Digital images can be provided by satellites with the same geographic region within a predefined interval. This feature enables us to monitor and control environmental and LULC changes between two different periods (Foody, 2002). Change detection is defined as a method used in remote sensing to identify differences in a given class between two or more periods. This process provides a quantitative analysis of the spatial distribution of studied phenomena and is, therefore, an essential and useful process for LULC monitoring (Foody, 2002). a post-classification detection technique was applied to obtain the change detection based on a pixel. Then, the classified image of two various periods analyzed utilizing change matrix (Weng, 2001) in ENVI5 to define the features of the differences from 1989 to 2015.

\subsection{Fuzzy Analytical Hierarchy process}

AHP is a broadly- applied famous multi-criteria decisionmaking method introduced in 1970 by Saaty (Werner et al., 2014; Saaty, 1990). The AHP was employed in various applications, principally because of their mathematical attributes, and for the ease of the required information implemented through it (Wu et al., 2007). The AHP is utilized to determine complex selection problems by using multi-level criteria for achieving the purposes, goals, sub-levels, and alternatives (Shareef et al., 2019). An assemblage of pairwise was used to achieve the comparisons which are employed to obtain the weights of the importance of choosing criteria and measure the efficiency of the choices through a specific approach (Pourghasemi et al., 2016). For combining the abilities, ideas, and opinions of 
a decision-maker, the linguistic predicting is converted to fuzzy numbers. Fuzzy AHP improves the capacity of the decision-making manner in any observation than conventional AHP (Zamani-Sabzi et al., 2016). The geometric mean method proposed by Buckley (Buckley, 1985) was adopted to make a comparison between the features, to calculate the fuzzy number and final weight of each used element, the linguistic terms were expressed in different importance level as shown in Table 2.

Table 2. The definition of fuzzy quantities (Huang \& Peng, 2012)

\begin{tabular}{|l|l|}
\hline Fuzzy Numbers & \multicolumn{1}{|c|}{ Linguistic Variable } \\
\hline$(1,1,1)$ & Equally significant \\
\hline$(2,3,4)$ & Moderately significant \\
\hline$(4,5,6)$ & Strongly significant \\
\hline$(6,7,8)$ & Very strongly significant \\
\hline$(8,9,9)$ & Extremely significant \\
\hline$(x-1, x, x+1)$ & $\begin{array}{l}\text { Intermediate values between adjacent } \\
\text { scale values }\end{array}$ \\
\hline
\end{tabular}

These linguistic terms are then converted into fuzzy triangular numbers (TFNs) as a membership function which can be described as:

$$
\mu_{\tilde{N}}(x)=\left(\tilde{a}_{i j}\right)=\left\{\begin{array}{l}
\frac{x-1}{m-1} \ldots . . l \leq x \leq m \\
\frac{u-x}{u-m}, \ldots . m \prec x \leq u, \\
0
\end{array}\right.
$$

where $l, m$, and $u$ are referred to as the lower bound, the mean bound, and the upper bound, respectively (Wang et al., 2007). The local and final weights in fuzzy AHP can be calculated as the following steps: Step 1: creating a fuzzified pairwise comparison matrix as the following: $\tilde{\mathrm{A}}=\left(\tilde{a}_{i j}\right)=$

$$
\left[\begin{array}{cccc}
(1,1,1) & \left(l_{12}, m_{12}, u_{12}\right) & \ldots & \left(l_{1 n}, m_{12}, u_{12}\right) \\
\left(l_{21}, m_{21}, u_{21}\right)^{-1} & (1,1,1) & \ldots & \left(l_{2 n}, m_{2 n}, u_{2 n}\right) \\
\vdots & \vdots & \ddots & \vdots \\
\left(l_{n} 1, m_{n} 1, u_{n 1}\right)^{-1} & \left(l_{2 n}, m_{2 n}, u_{2 n}\right)^{-1} & \ldots & (1,1,1)
\end{array}\right]
$$

where $n$ is the number of elements used in this level, and $\tilde{a}_{i j}=1 / \tilde{a}_{j i}$. And

$$
\begin{aligned}
& \tilde{a}_{i j}=\left(l_{i j}, m_{i j}, u_{i j}\right) ; \\
& \left(\tilde{a}_{i j}\right)^{-1}=\left(\frac{1}{u_{i j}}, \frac{1}{m_{i j}}, \frac{1}{l_{i j}}\right),
\end{aligned}
$$

where $i, j=1,2, \ldots . n$ and $i \neq j$.

Step 2: After construction of the fuzzified pairwise comparison matrix of entered elements, the fuzzy geometric mean value $\tilde{r}_{i}$ can be calculated as:

$$
\tilde{r}_{i}=\tilde{A}_{1} \otimes \tilde{A}_{2}=\left(\left(l_{1}, m_{1}, u_{1}\right) \otimes\left(l_{2}, m_{2}, u_{2}\right) \otimes \ldots . . . a_{i n}\right)^{1 / n} .
$$

Step 3: the final fuzzy weight is calculated by

$$
\tilde{w}_{i}=\tilde{r}_{i} \otimes\left(\tilde{r}_{1} \oplus \tilde{r}_{2} \oplus \ldots \oplus \tilde{r}_{n}\right)^{-1} .
$$

In some cases, the produced weights will be normalized if the sum of generated weights is not equal to one.

\section{Result and discussion}

\subsection{Accuracy assessment of classification}

All LULC features was compared to the testing, data to evaluate the efficiency of the classifier.the overall accuracy, kappa coefficient, and the producer's and user's efficiencies were calculated using the confusion matrix. The confusion matrix approach is often used for the evaluation of land-cover classification results. The result of error matrix components are illustrate in Table 3.

The accuracy assessement were applied on three used images 1989, 2002 and 2015. The finding reveals the a overall accuracy of $97.0939 \%, 98.9199 \%$ and $99.5817 \%$ for 1989, 2002 and 2015 respectively. while The Kappa coefficients were 97.0939, 0.9840 and 0.9911 for 1989, 2002 and 2015 respectively. All the procedure and users accuracies also calculated and listed in Table 3.

\subsection{LULC changes analysis}

Figure 3 shows the spatial distribution of the four land-

\begin{tabular}{|c|c|c|c|c|c|c|}
\hline \multirow[b]{2}{*}{ Classes } & \multicolumn{2}{|c|}{1989} & \multicolumn{2}{|c|}{2002} & \multicolumn{2}{|c|}{2015} \\
\hline & $\begin{array}{l}\text { Producer's } \\
\text { accuracy \% }\end{array}$ & $\begin{array}{c}\text { User's } \\
\text { accuracies }\end{array}$ & $\begin{array}{l}\text { Producer's } \\
\text { accuracy \% }\end{array}$ & $\begin{array}{c}\text { User's } \\
\text { accuracies }\end{array}$ & $\begin{array}{l}\text { Producer's } \\
\text { accuracy \% }\end{array}$ & $\begin{array}{c}\text { User's } \\
\text { accuracies }\end{array}$ \\
\hline Urban & 94.69 & 97.74 & 96.68 & 97.62 & 98.08 & 97.89 \\
\hline Vegetation & 92.52 & 98 & 98.44 & 98.83 & 97.60 & 97.98 \\
\hline Barren area & 98.96 & 95.69 & 99.68 & 99.21 & 99.84 & 99.72 \\
\hline Water & 98.91 & 99.86 & 98.91 & 99.92 & 99.61 & 100 \\
\hline Overall accuracy & \multicolumn{2}{|c|}{$97.0939 \%$} & \multicolumn{2}{|c|}{$98.9199 \%$} & \multicolumn{2}{|c|}{$99.5817 \%$} \\
\hline Kappa confidents & \multicolumn{2}{|c|}{0.9504} & \multicolumn{2}{|c|}{0.9840} & \multicolumn{2}{|c|}{0.9911} \\
\hline
\end{tabular}
cover classes of classified images of 1989 . It can be seen that the dominant class is the Barren area, representing around $85.09 \%$ of the study area with $2,927.3814 \mathrm{~km}^{2}$. In contrast, the water bodies' class has the smallest

Table 3. Error Matrix (\%) comparing the image classification of 1989, 2002, and 2015 to the reference data 


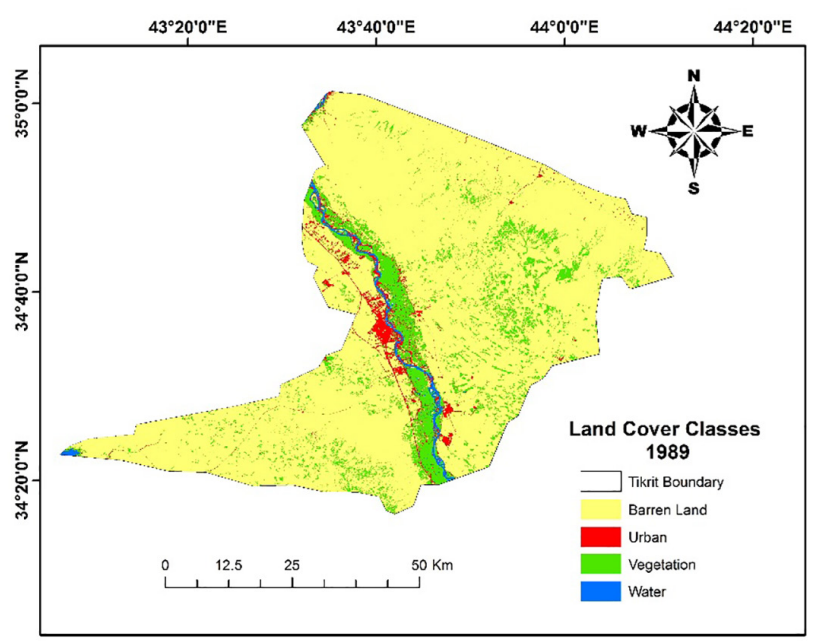

Figure 3. Classified map of LULC, 1989

area around $38.2869 \mathrm{~km}^{2}$ which represented $1.11 \%$ of the study area. Vegetation had a second percentage of study area around $11.05 \%$, which covers approximately $380.0727 \mathrm{~km}^{2}$. Finally, the same figure shows the urban class with $2.75 \%$ percentage of the study area and around $94.6971 \mathrm{~km} 2$. Figure 4 illustrates the spatial distribution of the land-cover classes of image 2002. The most significant class is the Barren area represented around $79.52 \%$ of the study area with $2,735.8623 \mathrm{~km}^{2}$. while the water bodies' class has the smallest area around $36.8955 \mathrm{~km}^{2}$, which represented $1.07 \%$ of the study area. Vegetation had a second percentage of study area around $16.56 \%$ which covers approximately $569.5659 \mathrm{~km}^{2}$. Finally, the urban class has a $2.85 \%$ percentage of the study area and around $98.1189 \mathrm{~km}^{2}$. And also Figure 5 states the spatial distribution of the land-cover classes of the image in 2015. It is clear from the figure that the Barren area class is covered in the dominate area with a ratio of $74.97 \%$ and area about $2,579.4468 \mathrm{~km}^{2}$. The smallest area is covered by the water bodies' class, which has $89.3232 \mathrm{~km}^{2}$ and a $2.6 \%$ ratio. Vegetation had a second percentage of study area around $15.33 \%$, which covers $527.4819 \mathrm{~km}^{2}$. The last class is urban with $244.1862 \mathrm{~km}^{2}$ and a rate of $7.1 \%$. The result of chage detection of LULC can be shown in Table 4.

However, the result of change detection percentage of various LULC for different periodcan be showed in Figure 6.

The figure shows a distinct variation in classes relative to the time period. The percentage of urban areas in the years 1989 and 2000 is somewhat close while the

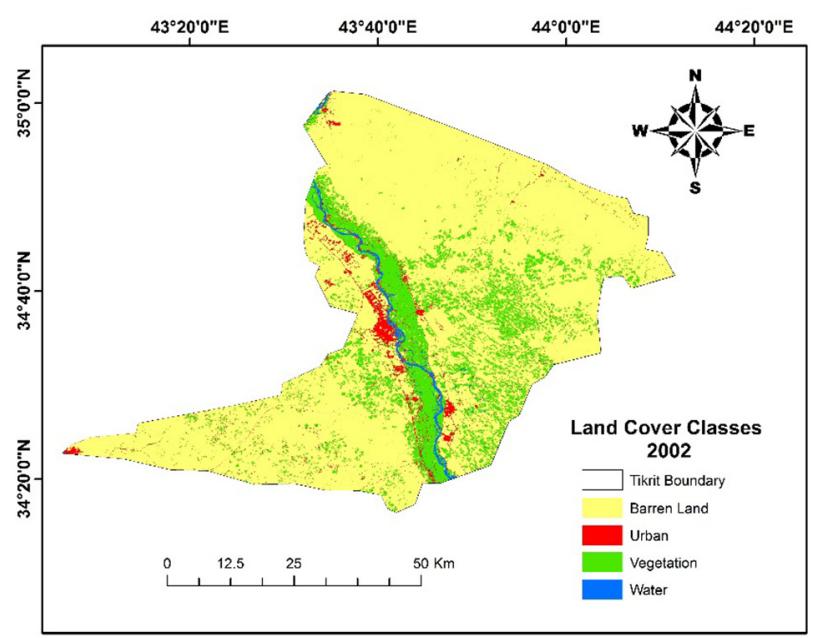

Figure 4. Classified map of LULC, 2002

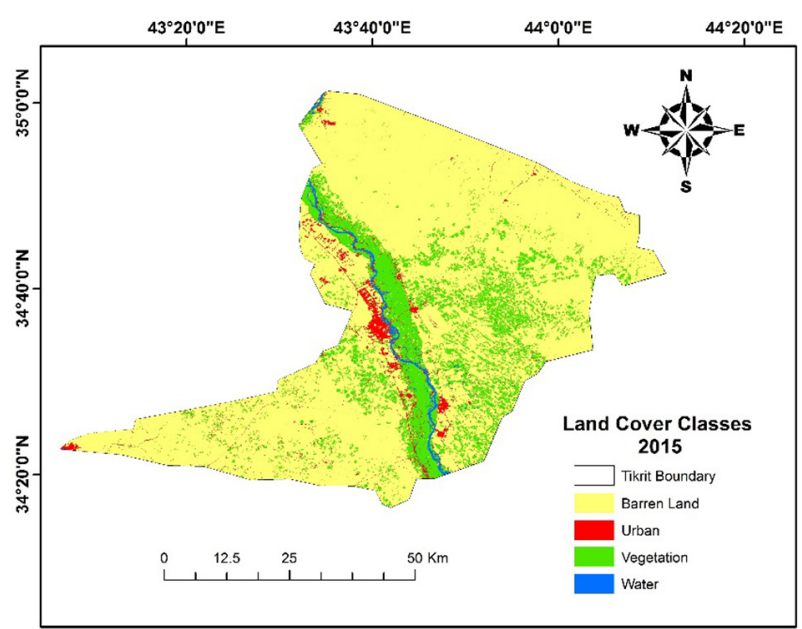

Figure 5. Classified map of LULC, 2015

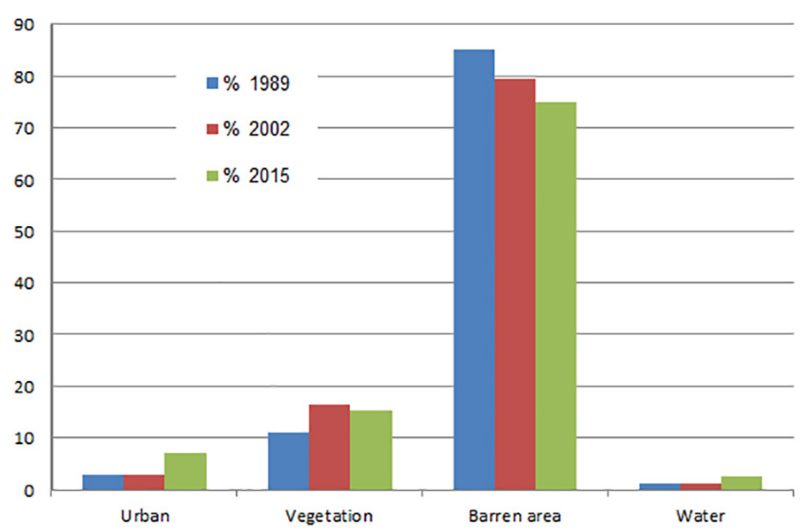

Figure 6. The percentages of LULC classes in three periods

Table 4. LULC statistics of the Tikrit City; in 1989, 2002, in 2015

\begin{tabular}{|l|c|c|c|c|c|c|}
\hline \multirow{2}{*}{ Classes } & \multicolumn{2}{|c|}{1989} & \multicolumn{2}{c|}{2002} & \multicolumn{2}{c|}{2015} \\
\cline { 2 - 7 } & Area in $\mathrm{km}^{2}$ & Percentage \% & Area in $\mathrm{km}^{2}$ & Percentage \% & Area in km ${ }^{2}$ & Percentage \% \\
\hline Urban & 94.6971 & 2.75 & 98.1189 & 2.85 & 244.1862 & 7.1 \\
\hline Vegetation & 380.0727 & 11.05 & 569.5659 & 16.56 & 527.4819 & 15.33 \\
\hline Barren area & $2,927.3814$ & 85.09 & $2,735.8623$ & 79.52 & $2,579.4468$ & 74.97 \\
\hline Water & 38.2869 & 1.11 & 36.8955 & 1.07 & 89.3232 & 2.6 \\
\hline
\end{tabular}


increasing of urban change in 2015 is evident. The proportion of vegetation has gradually increased in recent years, which in turn depends on the availability of rain and wells available in the study area.For barren areas, the proportion has been reduced due to the increase in the urban in addition to the clear increase in water and vegetation.

\subsubsection{Analysis of LULC change in short and long term}

The short term change detection involved two periods; 1989-2002 and 2002-2015 which spatial distributions are illusterated in Figure 7 and Figure 8 with more details dipected in Tables 5 and Table 6. The driving forces of the changes were also identified based on the finding from analysis. In the first period (1989-2002), the noted changes were the decrease in the barren land from $2,927.3814 \mathrm{~km}^{2}$ to $2,735.8623 \mathrm{~km}^{2}$, which converted to other classes mostly vegetation and urban. This reduction of barren area is attributed to the development of irrigation that supported by government in that period. In second period (2002-2015), the decline

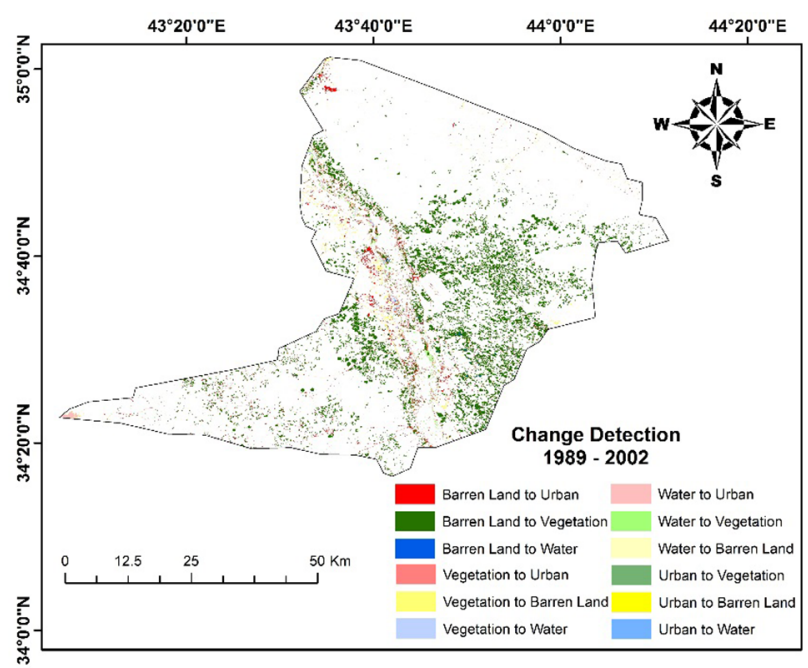

Figure 7. The spatial distribution of LULC changes during 1989-2002

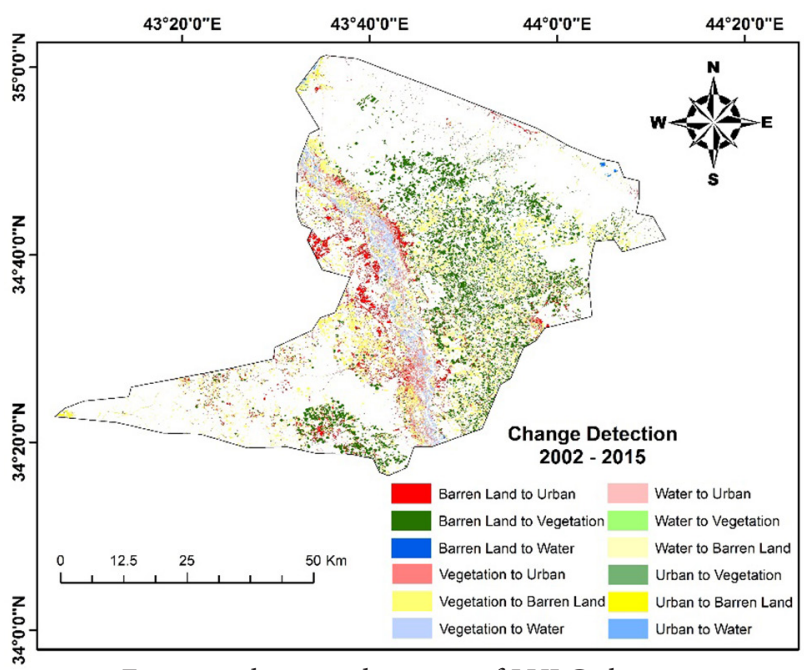

Figure 8. the spatial pattern of LULC changes during 2002-2015 was followed by another decrease around $156.4155 \mathrm{~km}^{2}$ as net change. Vegetation has two different phases increasing, followed by little decreasing from $16.56 \%$ and $15.33 \%$. The increasing in vegetation in (1989-2002) is belonging to the iiregation system, spreading in wells, contribution of the government to support the agricularal field. However, the urban class witnessed a slight increase in 1989-2002 followed by a marked increase in the 2002-2015 with an estimated area of $146.0673 \mathrm{~km}^{2}$ at the expense of water. This increase is based on the urban expansion resulting from the rise in the population in that period. Moreover, the class of water was fluctuating in the change, where it witnessed in the first short period a minimal decrease change while increasing in change of the second short period with a percentage of $1.07 \%$ to $2.6 \%$.

\subsubsection{Long term change detection analysis}

26 years were examined for studing the changes of LULC in the long term on the study area. Figure 9 and Table 5 illusterated the significant changes occurred during that period. Among these changes, the barren land level decline $10.12 \%$ with a net change of area about $347.9346 \mathrm{~km}^{2}$, which is a large area compared to other categories. This reductionin area can be attributed to several reasons, (1) climate change, (2) increased plant production, and (3) urban growth. The urban population area have also increased significantly from $94,697 \mathrm{~km}^{2}$ to $244,182 \mathrm{~km}^{2}$ as a natural result of the continuous growth in population rates with the rise in living income. Water and vegetation seasons increased during the entire study period. Vegetation area were increased up to $147.4092 \mathrm{~km}^{2}$. Also, water area increased from $38.2869 \mathrm{~km}^{2}$ to $89.3232 \mathrm{~km}^{2}$, with a percentage of $1.49 \%$. Thus, most of the increases have happened in urban variety, vegetation, and water at the expense of barren land,where $9.6318 \mathrm{~km}^{2}$ was turned to urban areas, $43.8534 \mathrm{~km}^{2}$ was converted to vegetation, and $5.6106 \mathrm{~km}^{2}$ was converted to water.

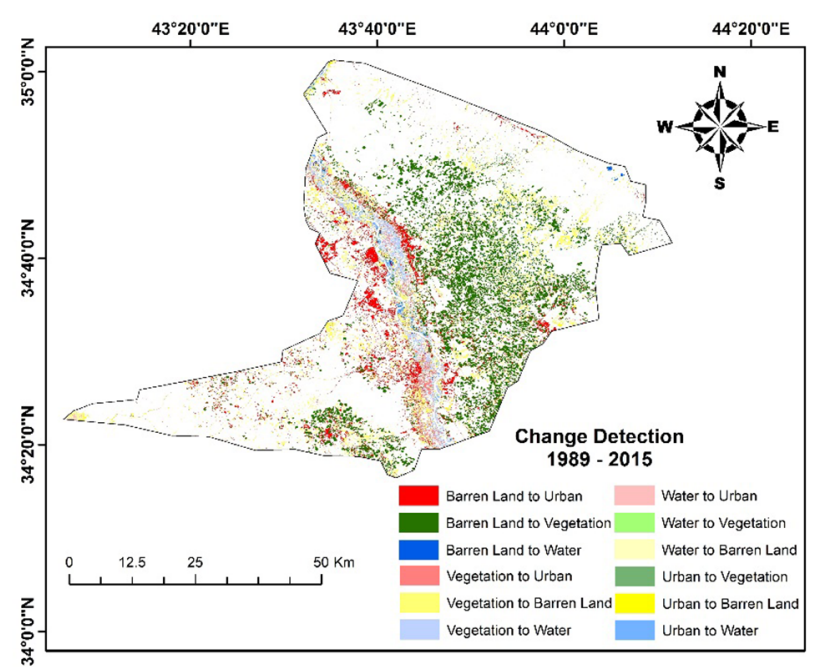

Figure 9. The spatial pattern of LULC changes during 1989-2015 
Table 5. The confusion matrix of change area between 1989 and 2015

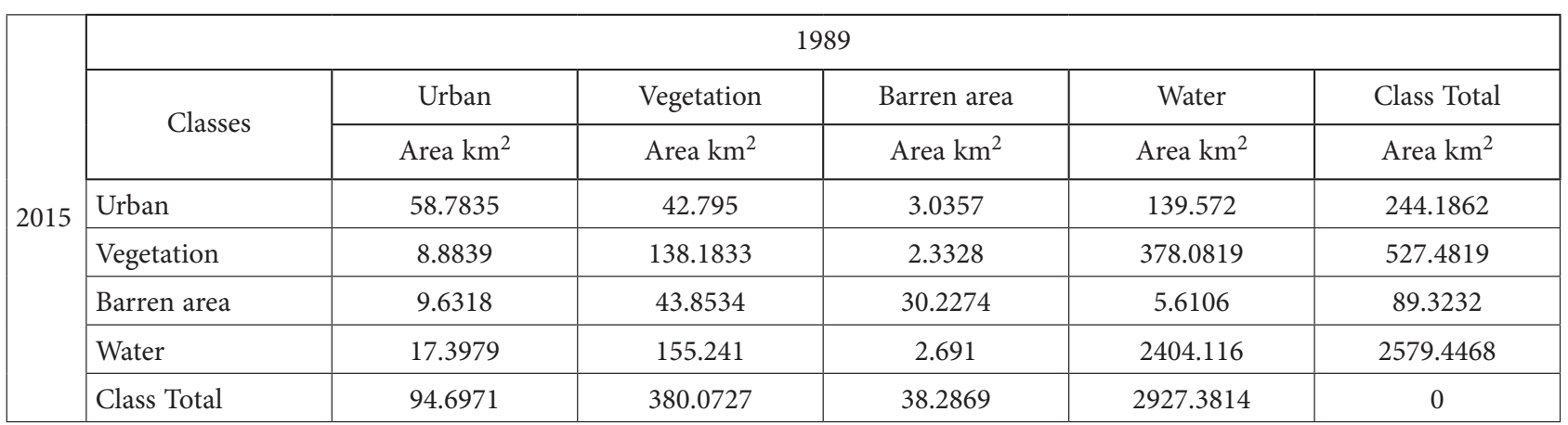

\subsection{FAHP analysis}

Data extracted by change detection was directly used in the method of fuzzy AHP. The authors' vision was taken according to the scale of the importance of 1 to 6 . Then the matrix of pairwise comparisons was generated for degradation and reclamation criteria using the linguistic variables. These criteria are representing by the land use / land cover change detection classes, which are ranging 6 , $5,4,3,2$, and 1 , respectively, according to the significance of each factor. The produced matrix was transformed into the fuzzified number, as illustrated in Table 1.

The indications of degradation in this paper are representing by converting the vegetation, water, and urban to the barren area and also converting vegetation and water features to the urban.

The fuzzified mean weight and the final weight of the studied criteria were calculated using Eqs (4) and (5). Table 7 shows the Fuzzy geometric mean and final weights of the entire criteria.

\section{Degradation map production}

In this paper, criteria have been specified to study the degree of degradation and then create a map of evaluation. These criteria including vegetation, water, urban (built up and road) and barren factor and four evaluation items as high, moderate, low, and no change were used in GIS software integrated with fuzzy-AHP; these features were combined to generate an environmental index (Eq. (7)) to produce a degradation and reclamation maps for study area.

$$
\begin{aligned}
& D M I=0.348 \times V B+0.329 \times W B+ \\
& 0.182 \times U B+0.086 \times V U+0.055 \times W U,
\end{aligned}
$$

where $D M I$ refers to the degradation map index, $V B$ is the changing of vegetation to barren, and $W B$ is the changing of water to barren, $U B$ is the changing of urban to barren, $V U$ is the changing of vegetation to urban and $W U$ is the changing of water to urban. In the same time, the reclamation index can be calculated using the following:

Table 6. Pairwise comparison matrix of degradation according to the authors' vision

\begin{tabular}{|l|c|c|c|c|c|}
\hline \multicolumn{1}{|c|}{ Criteria } & $\begin{array}{c}\text { Vegetation to } \\
\text { Barren }\end{array}$ & Water to Barren & Urban to Barren & $\begin{array}{c}\text { Vegetation to } \\
\text { Urban }\end{array}$ & Water to Urban \\
\hline Vegetation to Barren & $(1,1,1)$ & $(1,2,3)$ & $(2,3,4)$ & $(3,4,5)$ & $(4,5,6)$ \\
\hline Water to Barren & $(1 / 3,1 / 2,1)$ & $(1,1,1)$ & $(1,2,3)$ & $(2,3,4)$ & $(3,4,5)$ \\
\hline Urban to Barren & $(1 / 4,1 / 3,1 / 2)$ & $(1 / 3,1 / 2,1)$ & $(1,1,1)$ & $(1,2,3)$ & $(2,3,4)$ \\
\hline Vegetation to Urban & $(1 / 5,1 / 4,1 / 3)$ & $(1 / 4,1 / 3,1 / 5)$ & $(1 / 3,1 / 2,1)$ & $(1,1)$ & $(1,2,3)$ \\
\hline Water to Urban & $(1 / 6,1 / 5,1 / 4)$ & $(1 / 5,1 / 4,1 / 3)$ & $(1 / 4,1 / 3,1 / 2)$ & $(1 / 3,1 / 2,1)$ & $(1,1,1)$ \\
\hline
\end{tabular}

Table 7. Fuzzy geometric mean and final weight of the degradation criteria

\begin{tabular}{|c|c|c|c|c|}
\hline Criteria & $\begin{array}{c}\text { Fuzzy geometric mean } \\
\text { value } \tilde{r}_{i}\end{array}$ & $\begin{array}{c}\text { Fuzzy weight } \\
\tilde{w}_{i}\end{array}$ & $\begin{array}{c}\text { Fuzzy mean weight } \\
\tilde{w}_{i}\end{array}$ & Normalization of weight \\
\hline V to B & $(1.888,2.605,3.245)$ & $(0.217,0.413,0.755)$ & 0.462 & 0.348 \\
\hline W to B & $(1.186,1.861,2.783)$ & $(0.121,0.265,0.602)$ & 0.329 & 0.329 \\
\hline U to B & $(0.637,1.000,1.565)$ & $(0.065,0.143,0.339)$ & 0.182 & 0.182 \\
\hline V to U & $(0.358,0.537,0.667)$ & $(0.036,0.077,0.144)$ & 0.086 & 0.086 \\
\hline W to U & $(0.227,0.302,0.451)$ & $(0.023,0.043,0.098)$ & 0.055 & 0.055 \\
\hline
\end{tabular}




$$
\begin{aligned}
& R M I=0.348 \times B V+0.329 \times B W+ \\
& 0.182 \times B U+0.086 \times U V+0.055 \times U W .
\end{aligned}
$$

The analysis of degradation map using the produced model of degradation (Eq. (7)) including all factors that transformed into the bare soil (barren) or converted to the urban area. Degradations index is specifically located in areas with population growth and residential areas and areas close to residential communities or near highways. The notable degeneration (Figure 10) is more manifest in different municipalities that have beheld a fast and unlimited and irregular building. Those new messy urban areas remain to need the infrastructure and requirement of living. Low degradation is concentrated in a little area beside the tigress river in the northwest of the Tikrit city. The small area is representing by the transformation of water body to the urban (buildings or roads). This transformation is because of the spread of islands on both sides of the Tigris River due to lack of water levels, which led to an increase in land and, thus, an increase in construction areas around the river.

Due to commercial improvement, fast population increase, and growth of rural regions surrounding in the city, expansion of building on arable agricultural land, it displays an inevitable manner for changing the vegetation to the urban. Although this change has shown low in the edges of the Tigris River, it is considered one of the indicators of deterioration in that area. The study clarified that variations in land use are developing quickly in small time or a long time. The degradation of the vegetation field is transformed into the barren soil which represents the high percentage of the degradation in the city. All area of vegetation along 1989 to 2015 is assigned as deterioration to the barren lands. Thus, the analysis of degradation factor that environmental loss associated with vegetation development which perceived in various areas in Tikrit city especially in the North East, which can be attributed to the lack of rain in that period, which in turn led to the drying of some wells and the reluctance of farmers to agriculture due to wars. Thus, the progressive development in not well-prepared urban growth will perpetually be at the amount of barren and vegetation in the region of study. Consequently, the concerned municipalities require building strategies to spout this case by readdressing the urban expansion forward the weak bare soil and in hills parts of the Tikrit communities, to preserve the agricultural area.

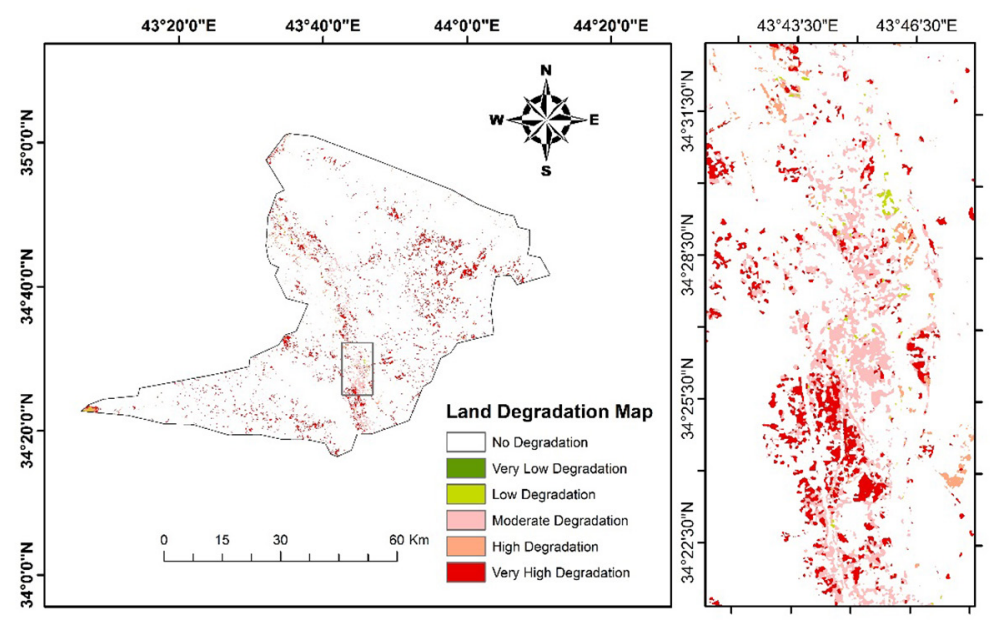

Figure 10. degradation map of Tikrit city

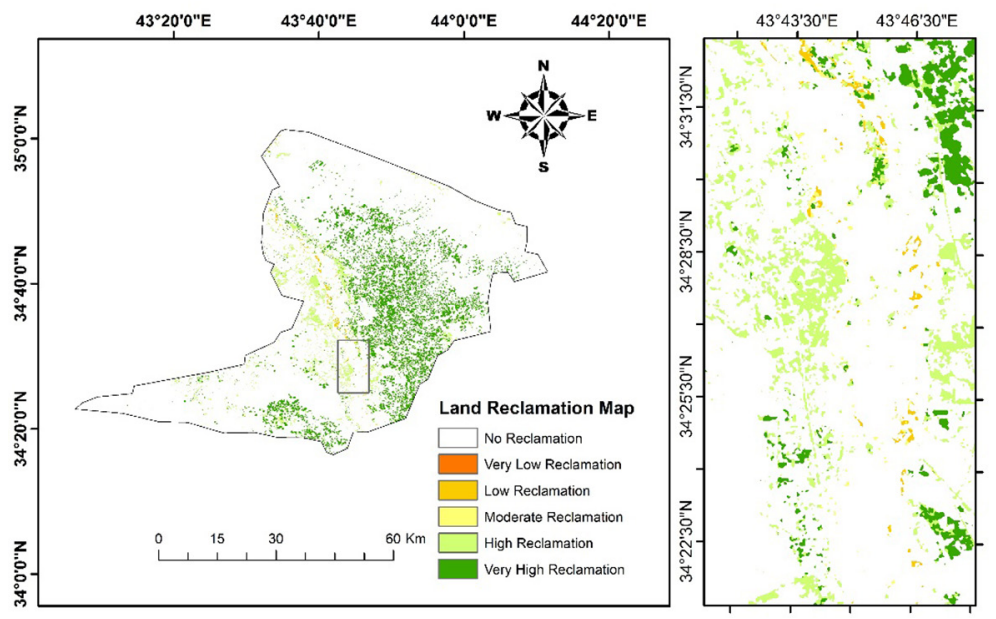

Figure 11. Reclamation map of Tikrit city 
In this study, the reclamation index refers to all the factors that have changed from arid lands to agricultural lands, plants, or lands containing water sources. These factors included in the reclamation index resulting from the application of the FAHP method, which gave weight to each element of reclamation as explained in Eq. (8). The resulting reclamation map (Figure 11) was classified into no change, very low, low, moderate, moderate to high and high to interpret the spatial distribution of the degree of soil reclamation. The high reclamation is referring to the transformation of the barren to the vegetation which is separated in the most significant part of the Tikrit city especially in the northeast and south of the city for the long-time period 1989 to 2015, while the moderate to high reclamation was in the zones which are close to the Tigris river. Most of these areas are converted to water and are close to the water source or to the valleys and depressions area that are propagated in that area. A small percentage of lands were converted to green zones in urban areas of the city that expanded on both sides of the Tigris River and the nearby regions.

\section{Conclusions}

With the increasing development in the size of the buildings built and the urban and population expansion in the city, the evaluation of land use and vegetation cover and its changes are essential factors for decision-makers and the design of cities and the development of future strategies to address urban growth. The present study endeavored to examine the temporal LULC through long-time years 1989, 2002 to 2016, and measuring the changes in different factors using FAHP and GIS techniques. The FAHP model is implemented to produce two models and then two maps of degradation and reclamation of the soil for Tikrit city. The most significant layer in the generated land degradation index was the layer of vegetation transformation to barren, which had the highest weight, while immediately followed by the water to barren, and then other factors characterized by small influence or low impact. The combination of FAHP and GIS techniques throughout using satellite data gave more flexibility to deals with information to obtain the suitable weight of criteria. The FAHP decision-making approach allows users and experts to efficiently choose further proper and diverse criteria to study the changes in LULC.

\section{References}

Aburas, M. M., Ahamad, M. S. S., \& Omar, N. Q. (2019). Spatiotemporal simulation and prediction of land-use change using conventional and machine learning models: A review. Environmental Monitoring and Assessment, 191(4), 205. https://doi.org/10.1007/s10661-019-7330-6

Ajaj, Q. M., Pradhan, B., Noori, A. M., \& Jebur, M. N. (2017). Spatial monitoring of desertification extent in western Iraq using Landsat images and GIS. Land Degradation \& Development, 28(8), 2418-2431. https://doi.org/10.1002/ldr.2775
An, R., Wang, H.-L., Feng, X.-Z., Wu, H., Wang, Z., Wang, Y., Shen, X.-J., Lu, C.-H., Quaye-Ballard, J. A., Chen, Y.-H., \& Zhao, Y.-H. (2017). Monitoring rangeland degradation using a novel local NPP scaling based scheme over the "Three-River Headwaters" region, hinterland of the Qinghai-Tibetan Plateau. Quaternary International, 444(Part A), 97-114. https://doi.org/10.1016/j.quaint.2016.07.050

Buckley, J. J. (1985). Fuzzy hierarchical analysis. Fuzzy Sets and Systems, 17(3), 233-247.

https://doi.org/10.1016/0165-0114(85)90090-9

Feizizadeh, B., Roodposhti, M. S., Jankowski, P., \& Blaschke, T. (2014). A GIS-based extended fuzzy multi-criteria evaluation for landslide susceptibility mapping. Computers \& Geosciences, 73, 208-221. https://doi.org/10.1016/j.cageo.2014.08.001

Foody, G. M. (2002). Status of land cover classification accuracy assessment. Remote Sensing of Environment, 80(1), 185-201. https://doi.org/10.1016/S0034-4257(01)00295-4

Gao, J., \& Liu, Y. (2008). Mapping of land degradation from space: A comparative study of Landsat ETM+ and ASTER data. International Journal of Remote Sensing, 29(14), 40294043. https://doi.org/10.1080/01431160801891887

Gao, J., \& Liu, Y. (2010). Determination of land degradation causes in Tongyu County, Northeast China via land cover change detection. International Journal of Applied Earth $\mathrm{Ob}$ servation and Geoinformation, 12(1), 9-16. https://doi.org/10.1016/j.jag.2009.08.003

Hadi, S. J., Shafri, H. Z., \& Mahir, M. D. (2014). Factors affecting the eco-environment identification through change detection analysis by using remote sensing and GIS: A case study of Tikrit, Iraq. Arabian Journal for Science and Engineering, 39(1), 395-405. https://doi.org/10.1007/s13369-013-0859-8

Hailemariam, S., Soromessa, T., \& Teketay, D. (2016). Land use and land cover change in the Bale Mountain Eco-Region of Ethiopia during 1985 to 2015. Land, 5(4), 41. https://doi.org/10.3390/land5040041

Higginbottom, T. P., \& Symeonakis, E. (2014). Assessing land degradation and desertification using vegetation index data: Current frameworks and future directions. Remote Sensing, 6(10), 9552-9575. https://doi.org/10.3390/rs6109552

Huang, J.-H., \& Peng, K.-H. (2012). Fuzzy Rasch model in TOPSIS: A new approach for generating fuzzy numbers to assess the competitiveness of the tourism industries in Asian countries. Tourism Management, 33(2), 456-465. https://doi.org/10.1016/j.tourman.2011.05.006

Metternicht, G. (1999). Change detection assessment using fuzzy sets and remotely sensed data: An application of topographic map revision. ISPRS Journal of Photogrammetry and Remote Sensing, 54(4), 221-233. https://doi.org/10.1016/S0924-2716(99)00023-4

Olofsson, P., Foody, G. M., Stehman, S. V., \& Woodcock, C. E. (2013). Making better use of accuracy data in land change studies: Estimating accuracy and area and quantifying uncertainty using stratified estimation. Remote Sensing of Environment, 129, 122-131. https://doi.org/10.1016/j.rse.2012.10.031

Pourghasemi, H. R., Beheshtirad, M., \& Pradhan, B. (2016). A comparative assessment of prediction capabilities of modified analytical hierarchy process (M-AHP) and Mamdani fuzzy logic models using Netcad-GIS for forest fire susceptibility mapping. Geomatics, Natural Hazards and Risk, 7(2), 861885. https://doi.org/10.1080/19475705.2014.984247

Rawat, J., \& Kumar, M. (2015). Monitoring land use/cover change using remote sensing and GIS techniques: A case study of Hawalbagh block, district Almora, Uttarakhand, India. The Egyptian Journal of Remote Sensing and Space Science, 18(1), 77-84. https://doi.org/10.1016/j.ejrs.2015.02.002 
Rocchini, D., Boyd, D. S., Féret, J. B., Foody, G. M., He, K. S., Lausch, A., Nagendra, H., Wegmann, M., \& Pettorelli, N. (2016). Satellite remote sensing to monitor species diversity: Potential and pitfalls. Remote Sensing in Ecology and Conservation, 2(1), 25-36. https://doi.org/10.1002/rse2.9

Saaty, T. L. (1990). How to make a decision: The analytic hierarchy process. European Journal of Operational Research, 48(1), 9-26. https://doi.org/10.1016/0377-2217(90)90057-I

Shareef, M. A., Hasan, S. F., \& Ajaj, Q. M. (2018, October). Estimation and mapping of dates palm using Landsat-8 images: A case study in Baghdad city. In 2018 International Conference on Advanced Science and Engineering (ICOASE). Duhok, Iraq. https://doi.org/10.1109/ICOASE.2018.8548787

Shareef, M. A., Hassan, N. D., Hasan, S. F., \& Noori, A. M. (2019). Integrating of GIS and fuzzy multi-criteria method to evaluate land degradation and their impact on the urban growth of Kirkuk city, Iraq. International Journal of Advanced Science and Technology, 28(15), 800-815.

Shareef, M. A., Toumi, A., \& Khenchaf, A. (2014). Estimation of water quality parameters using the regression model with fuzzy K-means clustering. International Journal of Advanced Computer Science and Applications (IJACSA), 5(6), 151-157. https://doi.org/10.14569/IJACSA.2014.050624

Wang, L., Chu, J., \& Wu, J. (2007). Selection of optimum maintenance strategies based on a fuzzy analytic hierarchy process. International Journal of Production Economics, 107(1), 151-163. https://doi.org/10.1016/j.ijpe.2006.08.005
Weng, Q. (2001). A remote sensing? GIS evaluation of urban expansion and its impact on surface temperature in the Zhujiang Delta, China. International Journal of Remote Sensing, 22(10), 1999-2014. https://doi.org/10.1080/01431160152043676

Werner, A., Storie, C. D., \& Storie, J. (2014). Evaluating SARoptical image fusions for urban LULC classification in Vancouver Canada. Canadian Journal of Remote Sensing, 40(4), 278-290. https://doi.org/10.1080/07038992.2014.976700

Wu, C.-R., Lin, C.-T., \& Chen, H.-C. (2007). Optimal selection of location for Taiwanese hospitals to ensure a competitive advantage by using the analytic hierarchy process and sensitivity analysis. Building and Environment, 42(3), 1431-1444. https://doi.org/10.1016/j.buildenv.2005.12.016

Xiao, J., Shen, Y., Ge, J., Tateishi, R., Tang, C., Liang, Y., \& Huang, Z. (2006). Evaluating urban expansion and land use change in Shijiazhuang, China, by using GIS and remote sensing. Landscape and Urban Planning, 75(1-2), 69-80. https://doi.org/10.1016/j.landurbplan.2004.12.005

Zamani-Sabzi, H., King, J. P, Gard, C. C., \& Abudu, S. (2016). Statistical and analytical comparison of multi-criteria decision-making techniques under fuzzy environment. Operations Research Perspectives, 3, 92-117. https://doi.org/10.1016/j.orp.2016.11.001 